\title{
Pneumothorax during laparoscopic Nissen fundoplication
}

Devanand Mangar MD MA, Gary T. Kirchhoff MD, Jorge J. Leal MD, Richard Laborde MD, Eugene Fu MD
We present a case of $100 \%$ pneumothorax in a 41 -yr-old man with a history of gastritis and gastroesophageal reflux scheduled for Nissen fundoplication. The patient was anaesthetized, and insuffation of the abdominal cavity with carbon dioxide was performed uneventfully. There was an increase in the peak inspiratory pressure and wheezing was noted with a decrease in the arterial oxygen saturation to $91 \%$. An obstructive pattern was noted on the end tidal carbon dioxide monitor. The patient also had decreased breath sounds in the left lung field. The endotracheal tube was withdrawn $1.5 \mathrm{~cm}$ with equal breath sounds noted in both lung fields, but the wheezing persisted. At the end of the case the trocars were removed and the abdomen was deflated. The arterial oxygen saturation increased to $94 \%$ while breathing $\mathrm{F}_{1} \mathrm{O}_{2}$ of 1.0. A chest roentgenogram showed a $100 \%$ left pneumothorax. A left chest tube was placed with immediate improvement of the arterial oxygen saturation to $100 \%$. We recommend monitoring of arterial oxygen saturation, peak inspiratory pressures, and excursion of the chest for early diagnosis and prompt treatment of pneumothorax during laparoscopic procedures.

Nous présentons un cas de pneumothorax à $100 \%$ chez une homme de 41 ans possédant des antécédents de gastrite et de reflux oesophagien programmé pour une fondoplicature de Nissen. Le patient est anesthésié et l'insufflation de la cavité abdominale avec du gaz carbonique réalisée sans incident. On constate une augmentation de la pression inspiratoire de pointe et du wheezing avec une chute à $91 \%$ de la saturation en oxygène. Une courbe de type obstructif apparaît sur le capnographe. Le tube endotrachéal est retiré de $1,5 \mathrm{~cm}$, l'égalité de la ventilation aux deux plages pulmonaires est vérifiée mais $l e$ wheezing persiste. En fin d'intervention, les trocarts sont en-

\section{Key words}

COMPLICATIONS: pneumothorax;

SURGERY: laparoscopy.

From the Department of Anesthesiology, Tampa General Hospital, Tampa, Florida.

Address correspondence to: Dr. Mangar, Department of Anesthesiology, Tampa General Hospital, Davis Islands, Tampa, Florida 33606.

Accepted for publication IIth May, 1994. levés et l'abdomen est dégonflé. Un drain thoracique droit est inséré et la saturation en oxygène remonte immédiatement à $100 \%$. Nous recommandons le monitorage de la saturation artérielle en oxygène, de la pression inspiratoire de pointe et de l'excursion thoracique pendant les interventions laparascopiques.

The higher mortality and protracted hospital stay from laparotomy, and the recent improvement in instrumentation, have increased the popularity of laparoscopy. ' Laparoscopy has been extended to include appendicectomy, inguinal hernia repair, laparoscopic nephrectomy, splenectomy, hemicolectomy, and in our case Nissen fundoplication. ${ }^{2}$ The use of laparoscopy has eliminated the upper abdominal incision, and the impairment of pulmonary mechanics and ventilation. ${ }^{3}$ Consequently, patients can be discharged from the hospital earlier. We report the complication of left pneumothorax which occurred during laparoscopy for Nissen fundoplication. The pneumothorax was caused probably by a rent in the diaphragm during the procedure permitting gas to enter the left chest.

\section{Case report}

The patient was a 41-yr-old, 97-kg man undergoing laparoscopic Nissen fundoplication for gastritis, gastroesophageal reflux, and a hiatal hernia. His physical examination and laboratory values were within normal limits. Medications included ranitidine $150 \mathrm{mg}$ po twice daily.

General anaesthesia was induced with thiopentone 500 $\mathrm{mg} i v$ followed by succinylcholine $120 \mathrm{mg} i v$ to facilitate tracheal intubation with an 8.0 millimeter cuffed tracheal tube. Anaesthesia was maintained with oxygen and nitrous oxide in a 1:3 ratio and $1.5 \%$ inspired isoflurane. The patient also received atracurium $50 \mathrm{mg} i v$ for maintenance of neuromuscular blockade. Monitors included blood pressure, end-tidal carbon dioxide, ECG, oximetry, and nerve stimulator.

Abdominal insufflation was performed with carbon dioxide and the trocars were placed uneventfully. The patient was placed in a $30^{\circ}$ reverse Trendelenburg position to assist with surgical exposure. The peak inspiratory 
pressure was noted to have increased from 25 to $36 \mathrm{~cm}$ water after abdominal insufflation. Twenty minutes after surgery started it was noted through auscultation that the patient was wheezing. At this time, his peak airway pressure was $42 \mathrm{~cm}$ water. The arterial oxygen saturation decreased from 97 to $91 \%$ and an obstructive waveform pattern (capnogram similar to patients with chronic obstructive pulmonary disease) was noted on the end tidal carbon dioxide monitor. The patient was noted to have decreased breath sounds on the left lung field. The endotracheal tube was withdrawn $1.5 \mathrm{~cm}$ which produced equal breath sounds in both lung fields, but wheezing persisted. Several puffs of nebulized albuterol was administered which resulted in cessation of the wheezing. The peak airway pressure decreased to $40 \mathrm{~cm}$ water, the arterial oxygen saturation increased to $95 \%$, but the obstructive pattern persisted on the end tidal monitor.

The remainder of the operation was uneventful, except for a gradual decline in the arterial oxygen saturation to $92 \%$. The trocars were removed and the abdomen was deflated. The neuromuscular block was reversed with neostigmine $5 \mathrm{mg}$ and glycopyrrolate $1 \mathrm{mg} i v$, and the patient assumed spontaneous breathing. While breathing $\mathrm{FiO}_{2}$ of 0.3 , the arterial oxygen saturation decreased to $88 \%$ but increased to $94 \%$ on $\mathrm{FIO}_{2}$ of 1.0 . No wheezing was noted but there were no breath sounds on the left chest.

A chest roentgenogram confirmed the diagnosis of $100 \%$ left pneumothorax (Figure). A left chest tube was placed with immediate improvement of the arterial oxygen saturation to $100 \%$. The trachea was extubated and the patient was transported to the postanesthetic care unit. A repeat chest film revealed complete resolution of the pneumothorax. His postoperative course was uncomplicated. The chest tube was removed on the second postoperative day and the patient was discharged on the third postoperative day without any further problems.

\section{Discussion}

We present a case of right main stem intubation, pneumothorax, decreased saturation, wheezing, and increased peak inspiratory pressure during laparoscopic Nissen fundoplication. The patient was treated for the wheezing which subsided, and the tracheal tube was withdrawn. The arterial saturation decreased from $95 \%$ to $92 \%$, and decreased breath sounds were noted in the left lung despite correct positioning of the tracheal tube. While in the operating room, a chest roentgenogram revealed a left pneumothorax, which was drained with a left chest tube. The saturation instantly increased, and the tracheal tube was removed.

Laparoscopy is used by general surgeons to operate on patients in order to avoid incisions in the upper ab-

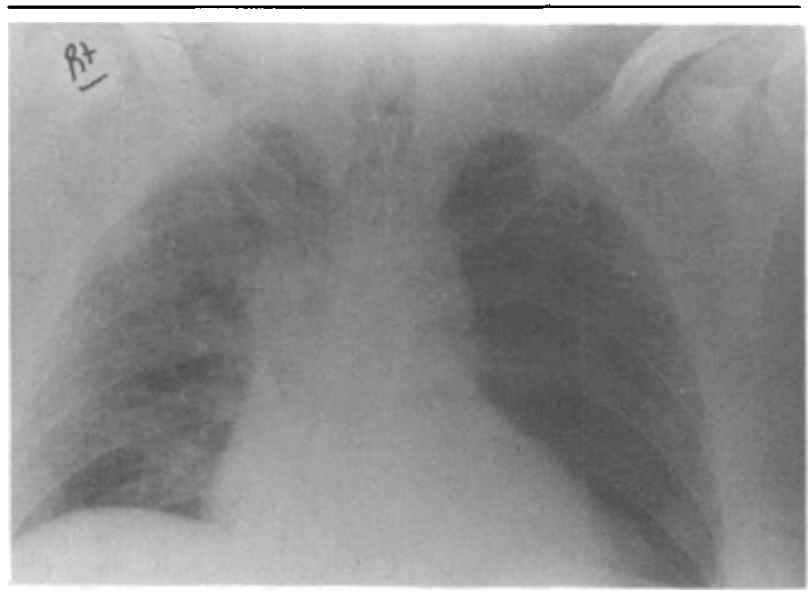

FIGURE Chest roentgenogram showing complete left pneumothorax.

domen that can cause detrimental changes in cardiopulmonary function. The mortality rate of eight per 100,000 laparoscopies has been reported with complications from cardiac arrhythmias, pulmonary embolism, bowel trauma, haemorrhage, and acute hypotension from compression of the inferior vena cava. ${ }^{4,5}$ Meyers et al. in a prospective study of 1518 patients reported a complication rate of $5.1 \% .^{6} \mathrm{~A}$ large European series reported an average mortality rate of $0.05 \%$ with a range of 0.014 to $0.13 \%{ }^{7}$ In a study of 100,000 cases Mintz reported the risk of laparoscopy to two events: first, the inevitable haemorrhage due to the insufflation needle, and second, the unforeseeable gas embolism.

Putensen-Himmer $e t$ al. compared open laparotomy with laparoscopic cholecystectomy. The main findings of their study were that, in the early postoperative period, lung volumes, including the functional reserve capacity, decreased significantly less after laparoscopic than open cholecystectomy. Recovery of lung volumes, including functional reserve capacity, to preoperative values was much improved after laparoscopic than after open cholecystectomy. The decrease in $\mathrm{PaO}_{2}$ was greater in the open laparotomy than in the laparoscopic group. However, no differences between the two groups were noted for $\mathrm{PaCO}_{2}$ and $\mathrm{pH}^{3}$

The escape of gas into the thoracic cavity through a congenital defect in the diaphragm (patent pleuroperitoneal canal) or from a tear in the diaphragm may result in pneumothorax. ${ }^{1,4}$ In our case, no defect could be demonstrated upon observation of the left diaphragm with the laparoscope. The pneumothorax was caused by a tear in the diaphragm during the fundoplication causing gas to enter the left pleural space. In this patient, tension pneumothorax did not develop in the presence of continuous positive pressure because of the communication 
between the pleural and the peritoneal cavities. This is a hindsight hypothesis, and had this not occurred, then a tension pneumothorax resulting in cardiac arrest could have occurred.

The use of the laparoscope for repair of hiatus hernia is an additional application of this relatively new surgical procedure. The advantages of laparoscopy compared with open laparotomy are shorter hospital stay, more rapid return to normal activity, less pain associated with the small limited incision and less postoperative ileus. ${ }^{2}$ However, the increasing popularity of this technique presents new challenges to anaesthetists and surgeons. As illustrated in this case, pneumothorax is always a concern, especially when the surgeon is working near the diaphragm. We recommend close monitoring of peak inspiratory pressures and the utilization of pulse oximetry to detect desaturation. The early recognition of this problem could avoid a disaster. The use of gasless laparoscopy with conventional surgical instruments in the presence of abdominal wall lift systems may expand the horizon of laparoscopy. ${ }^{9}$ Hence, a pneumothorax may be obviated in the absence of carbon dioxide as a distending medium.

We present a case of intraoperative pneumothorax secondary to a tear in the diaphragm during laparoscopic Nissen fundoplication. We recommend the monitoring of arterial oxygen saturation, peak inspiratory pressures, and excursion of the chest in order for early diagnosis and prompt treatment.

\section{References}

1 Calverley $R K$, Jenkins $L C$. The anaesthetic management of pelvic laparoscopy. Can Anaesth Soc J 1973; 20: 679-85.

2 Cunningham AJ, Brull SJ. Laparoscopic cholecystectomy: anesthetic implications. Anesth Anagl 1993; 76: 1120-33.

3 Putensen-Himmer G, Putensen C, Lammer H, Lingnau $W$, Aigner $F$, Benzer $H$. Comparison of postoperative respiratory function after laparoscopy or open laparotomy for cholecystectomy. Anesthesiology 1992; 77: 675-80.

4 Whiston RJ, Eggers KA, Morris RW, Stamatakis JD. Tension pneumothorax during laparoscopic cholecystectomy. Br J Surg 1991; 78: 1325.

5 Lee $C M$. Acute hypotension during laparoscopy: a case report. Anesth Analg 1975; 54: 142-3.

6 The Southern Surgeon Club. A prospective analysis of 1518 laparoscopic cholecystectomies. N Engl J Med 1991; 324: 1073-8.

7 Ponsky JL. Complications of laparoscopic cholecystectomy. Am J Surg 1991; 161: 393-5.

8 Mintz $M$. Risks and prophylaxis in laparoscopy: a survey of 100,000 cases. J Reprod Med 1977; 18: 269-72.
9 Smith RS, Fry WR, Tsoi EKM, et al. Gasless laparoscopy and conventional instruments: the next phase of minimally invasive surgery. Arch Surg 1993; 128: 1102-7. 